\title{
Increased cell proliferation in the rat anterior cingulate cortex following neonatal hypoxia: relevance to schizophrenia
}

\author{
Evelin L. Schaeffer • Franziska Kühn • Angelika Schmitt • \\ Wagner F. Gattaz • Oliver Gruber · Thomas Schneider-Axmann • \\ Peter Falkai • Andrea Schmitt
}

Received: 14 April 2012 / Accepted: 29 June 2012/Published online: 19 July 2012

(C) The Author(s) 2012. This article is published with open access at Springerlink.com

\begin{abstract}
As a consequence of obstetric complications, neonatal hypoxia has been discussed as an environmental factor in the pathophysiology of schizophrenia. However, the biological consequences of hypoxia are unclear. The neurodevelopmental hypothesis of schizophrenia suggests that the onset of abnormal brain development and neuropathology occurs perinatally, whereas symptoms of the disease appear in early adulthood. In our animal model of chronic neonatal hypoxia, we have detected behavioral alterations resembling those known from schizophrenia. Disturbances in cell proliferation possibly contribute to the pathophysiology of this disease. In the present study, we used postnatal rats to investigate cell proliferation in several brain areas following neonatal hypoxia. Rats were repeatedly exposed to hypoxia $\left(89 \% \mathrm{~N}_{2}, 11 \% \mathrm{O}_{2}\right)$ from
\end{abstract}

70th Birthday Prof. Riederer.

E. L. Schaeffer · W. F. Gattaz

Laboratory of Neuroscience (LIM-27),

Department and Institute of Psychiatry, Faculty of Medicine,

University of São Paulo, São Paulo, Brazil

F. Kühn · O. Gruber · T. Schneider-Axmann · P. Falkai ·

A. Schmitt $(\square)$

Department of Psychiatry and Psychotherapy,

Georg-August-University, von-Siebold-Str. 5,

37075 Göttingen, Germany

e-mail: aschmit@gwdg.de

\section{A. Schmitt}

Department of Psychiatry and Psychotherapy,

University of Würzburg, Füchsleinstr. 15,

97080 Würzburg, Germany

P. Falkai · A. Schmitt

Department of Psychiatry and Psychotherapy,

Ludwig-Maximilians-University, Nußbaumstr. 7,

80336 Munich, Germany postnatal day (PD) 4-8. We then evaluated cell proliferation on PD 13 and 39, respectively. These investigations were performed in the anterior cingulate cortex (ACC), caudate-putamen (CPU), dentate gyrus, and subventricular zone. Rats exposed to hypoxia exhibited increased cell proliferation in the ACC at PD 13, normalizing at PD 39. In other brain regions, no alterations have been detected. Additionally, hypoxia-treated rats showed decreased CPU volume at PD 13. The results of the present study on the one hand support the assumption of chronic hypoxia influencing transient cell proliferation in the ACC, and on the other hand reveal normalization during ageing.

Keywords Cell proliferation - Rat - Anterior cingulate cortex $\cdot$ Neonatal hypoxia $\cdot$ Schizophrenia

\section{Introduction}

In addition to genetic predisposition, the neurodevelopmental hypothesis of schizophrenia includes a number of environmental factors like obstetric and birth complications with hypoxia as a common factor possibly influencing the pathophysiology of the disease. The risk of schizophrenia has to be shown to increase with the severity and number of hypoxia-associated obstetric complications (Cannon et al. 1999; McNeil et al. 2000a; Dalman et al. 2001). Furthermore, twin studies revealed that fetal hypoxia was a predictor of smaller hippocampal volumes (McNeil et al. 2000b; Van Erp et al. 2002), increased ventricles and reduced cortical grey matter volume (Cannon et al. 2002), and early age of onset (Verdoux et al. 1997; Cannon et al. 2002) in schizophrenia patients. However, the consequences of hypoxia on the pathophysiology of the disease are unclear. The neurodevelopmental 
hypothesis of schizophrenia suggests that the onset of abnormal brain development occurs during the perinatal period, leading to symptoms of the disease in early adulthood (Weinberger 1996).

With respect to rat brain, the early postnatal period from postnatal day 4 to 8 is highly vulnerable to hypoxic damage (Ikonomidou et al. 1989). In contrast to humans, important steps of brain development in rats occur mainly postnatally and the brain growth spurt of early postnatal rats as well as overexpression of glutamatergic $\mathrm{N}$-methyl-D-aspartate (NMDA) receptors is comparable to the third trimester in humans (Dobbing and Sands 1979). Moreover, while neuron birth and differentiation are largely completed by the end of gestation, selected regions of the brain harbor neuronal precursor cells throughout life, thus offering an opportunity to investigate stem cell proliferation postnatally. In postnatal and adult brain, new neurons continue to be generated in two specific neurogenic areas, the subgranular zone (SGZ) of the hippocampal dentate gyrus (DG) and the subventricular zone (SVZ) of the lateral ventricles (Yamashima et al. 2007). In the medial prefrontal cortex of rats inclusive anterior cingulate cortex (ACC), adult cell proliferation and its stimulation have been observed as well, but stem cells did not differentiate into neurons (Kodama et al. 2004, Madsen et al. 2005). Adult neurogenesis is a multi-step process (proliferation, differentiation, migration, targeting, and synaptic integration). Thus, from the two neurogenic areas, new neurons migrate towards their final targets in other brain areas where they differentiate and integrate with local circuits (Ehninger and Kempermann 2008). New neurons leaving the SGZ migrate into the adjacent granule cell layer of the DG (Altman and Bayer 1990; Kuhn et al. 1996). Neurons that originate in the SVZ migrate, among others, to the olfactory bulb (Pencea et al. 2001; Bédard and Parent 2004; Shapiro et al. 2006), association neocortex including prefrontal cortex (Gould et al. 1999), and striatum (Bédard and Parent 2004).

Dysregulated neurogenesis during early adulthood has been observed in some animal models of schizophrenia, implicating that postnatal neurogenesis may contribute to a part of the symptoms of this disorder. Keilhoff et al. (2004b) demonstrated enhanced adult neurogenesis in the hippocampal SGZ in a rat ketamine model of schizophrenia. Ketamine, an antagonist of $N$-methyl-D-aspartate (NMDA) receptors, has been shown to mimic behavioral and biological aspects of schizophrenia in animals (Becker et al. 2003; Bernstein et al. 2003; Keilhoff et al. 2004a). Recently, Manning et al. (2012) documented increased adult neurogenesis in the granule cell layer of the DG in phospholipase C- $\beta 1$ knockout mice. Previous characterization of these mice demonstrated the presence of several schizophrenia-like endophenotypes (McOmish et al. 2008a, b).
In a previous study using a rat model of chronic neonatal hypoxia, we showed decreased NMDA receptor binding in the ACC, frontal regions, nucleus accumbens, and hippocampus of hypoxia-treated animals, as well as a deficit in prepulse inhibition of acoustic startle response (Schmitt et al. 2007; Fendt et al. 2008), which is also disrupted in schizophrenic patients and restored by antipsychotics (Braff et al. 1992; Van den Buuse et al. 2003; Kodama et al. 2004). In the present study, we used postnatal rats to investigate if there are indications of altered cell proliferation following neonatal hypoxia. We applied chronic, repeated hypoxia $\left(11 \% \mathrm{O}_{2}, 89 \% \mathrm{~N}_{2}\right)$ during $6 \mathrm{~h}$ from postnatal day 4 to 8 . We then evaluated cell proliferation on postnatal days, 13 and 39, respectively. These investigations were performed in the ACC, striatum, i.e., caudateputamen (CPU), DG, and SVZ.

\section{Materials and methods}

Animals and induction of neonatal hypoxia

Animal use procedures were in strict accordance with the NIH guidelines for the care and use of laboratory animals and had been approved by the local ethics committee. Forty male Sprague-Dawley rats (Animal Facility, University of Göttingen) were bred from 8 pregnant females (Charles River, Germany). Male litter mates were grown until examined on postnatal day (PD) 13 or 39 . The rats were housed in standard cages under a $12 \mathrm{~h}$ light/dark cycle with food and water available ad libitum. Chronic, repeated hypoxia $\left(11 \% \mathrm{O}_{2}, 89 \% \mathrm{~N}_{2}\right)$ was imposed from PD four to eight on 20 animal pups and their mothers by placing them in an air-tight plastic chamber for a period of $6 \mathrm{~h}$ per day. The 20 other pups were subjected to identical handling conditions and were placed in identical chambers but with regular oxygen concentrations $\left(21 \% \mathrm{O}_{2}=\right.$ normoxia; control animals) (Schmitt et al. 2007; Fendt et al. 2008; Sommer et al. 2010). During hypoxia, mothers were able to care for their pups.

\section{BrdU injection and brain tissue collection}

On PD 11, 20 hypoxia-treated (mean weight: $21.1 \pm$ $1.54 \mathrm{~g}$ ) and 20 control rats (mean weight: $25.5 \pm 1.42 \mathrm{~g}$ ) received intraperitoneal (i.p.) injection of 5-bromo-2deoxyuridine (BrdU; Sigma, Taufkirchen, Germany) four times every $2 \mathrm{~h}(75 \mathrm{mg} / \mathrm{kg}$ body weight, dissolved in $0.9 \%$ $\mathrm{NaCl}$ ), for labeling the newly dividing cells. BrdU, a thymidine analogue, is incorporated into the DNA of dividing cells during the S-Phase and is detected using a specific, monoclonal antibody (Gratzner 1982). To investigate the effect of postnatal hypoxia on stem cell proliferation, 10 
hypoxia-treated and 10 control rats were killed 2 days after BrdU injection (PD 13). Additionally, 10 hypoxia-treated and 10 control rats were allowed to survive 28 days after BrdU injection (PD 39). Rats were anesthetized with i.p. injection of ketamine $(100 \mathrm{mg} / \mathrm{kg}$ bw)/xylazine $(5 \mathrm{mg} / \mathrm{kg}$ bw) and killed by transcardial perfusion with Tyrode's solution followed by fixation with $4 \%$ paraformaldehyde in Sörensen buffer $0.2 \mathrm{M}, \mathrm{pH} 7.6 \quad\left(\mathrm{NaH}_{2} \mathrm{PO}_{4}\right.$ and $\mathrm{Na}_{2} \mathrm{HPO}_{4}$ ). The brains were dissected and postfixed in $4 \%$ paraformaldehyde for $2 \mathrm{~h}$ and subsequently immersed in $15 \%$ sucrose solution overnight at $4{ }^{\circ} \mathrm{C}$. The brain tissue was then stored until use at $-80{ }^{\circ} \mathrm{C}$.

\section{BrdU immunohistochemistry}

The brains were cut by cryostat in the coronal plane from frontal pole until the end of hippocampus into $60-\mu \mathrm{m}$-thick adjacent serial sections. Every sixth free-floating section was processed for immunohistochemical staining of incorporated BrdU. Brain sections were washed in TRISbuffered saline (TBS, $\mathrm{pH}$ 7.5) at room temperature (RT). Next, the sections were incubated with $0.6 \% \mathrm{H}_{2} \mathrm{O}_{2}$ for $30 \mathrm{~min}$ at RT to eliminate endogenous peroxidase activity. After washing in TBS, DNA was denaturated with $50 \%$ formamide/ $2 \times$ saline sodium citrate (SSC; $\mathrm{pH} 7.0$ ) for $2 \mathrm{~h}$ at $65{ }^{\circ} \mathrm{C}$ followed by acid $(2 \mathrm{~N} \mathrm{HCl})$. After washing in TBS, the sections were then incubated with $2 \mathrm{~N} \mathrm{HCl}$ for $30 \mathrm{~min}$ at $37^{\circ} \mathrm{C}$. Sections were washed in $100 \mathrm{mM}$ borate buffer $(\mathrm{pH}$ 8.5) for $10 \mathrm{~min}$ at RT to neutralize the acid. After washing in TBS, the sections were incubated for $60 \mathrm{~min}$ at RT with blocking solution A [ $2 \%$ bovine serum albumin (BSA) and $5 \%$ normal goat serum (NGS) in $0.25 \%$ Triton X-100TBS]. They were then incubated overnight at $4{ }^{\circ} \mathrm{C}$ with 1:500 anti-BrdU mouse monoclonal (Roche, Mannheim, Germany) diluted in blocking solution A. After washing in TBS, the sections were incubated for $60 \mathrm{~min}$ at RT with 1:400 biotinylated anti-mouse (Vectastain ABC Kit, Linaris, Wertheim, Germany) diluted in blocking solution B ( $2 \%$ BSA and $2 \%$ NGS in $0.25 \%$ Triton X-100-TBS). Sections were washed in TBS and subsequently incubated with avidin-biotinylated horseradish peroxidase complex (Vectastain ABC Kit) for $90 \mathrm{~min}$ at RT. After washing in TBS, sections were treated with diaminobenzidine (DAB; Vectastain ABC Kit) for $10 \mathrm{~min}$ at RT and subsequently washed in TBS. Finally, the sections were mounted on slides and coverslipped.

Stereological analysis

Regions were delineated according to the atlas of Paxinos and Watson (1986) (Fig. 1). BrdU-labeled cells were counted in serial sections in the ACC, CPU, DG, and SVZ (Fig. 2) using a stereological workstation, consisting of a modified light microscope (BX50; Olympus, Tokyo, Japan), Olympus Uplan Apo objectives $(1.5 \times, 20 \times$, $50 \times$ oil, $100 \times$ oil), motorized specimen stage for automatic sampling, electronic microcator, CCD color video camera, PC with frame grabber board, stereology software (StereoInvestigator; MicroBrightField, Williston, USA) and a 17-in. monitor. Boundaries of the regions of interest (ACC, CPU, DG, SVZ) (Fig. 1) were traced on video images displayed on the computer screen and total volumes of the delineated structures were calculated according to the Cavalieri principle (Schmitz and Hof 2005). With respect to the CPU, the total structure was delineated, while in the other regions we delineated areas of interest (Fig. 1). Total numbers of BrdU-positive cells were estimated using the optical disector (West et al. 1991; Schmitz 1998; Schmitz and Hof 2000, 2005). We performed a count of BrdUlabeled cells that came into focus within unbiased virtual counting spaces (Sterio 1984; Gundersen et al. 1988) distributed in a systematic-random fashion throughout the different regions of interest. Total estimated numbers of BrdU-labeled cells were calculated by the area that was sampled on each section of known thickness and the distance between the corresponding surfaces of the adjacent systematically sampled sections according to the Cavalieri method (Gundersen et al. 1988; West 1999).

\section{Statistical analysis}

Statistical analysis was performed using SPSS 17 software. The body weight gain data were analyzed by one-way ANOVA. Results of Kolmogorov-Smirnov tests showed normal distribution of cell number and structure volume data. Thus, comparisons between the hypoxia-treated rats and controls were performed using generalized linear model multivariate analysis (MANOVA), with treatment such as fixed factor and body weight as covariate. In all analyses, differences were considered statistically significant if $p$ value was smaller than 0.05. All data are expressed as mean $\pm \mathrm{SD}$.

\section{Results}

Postnatal day 13

On PD 13, the hypoxia-treated rats showed lower body weight than controls (hypoxia: $25.26 \pm 2.07 \mathrm{~g}$ vs. controls: $29.01 \pm 1.83 \mathrm{~g}$; ANOVA: $F=18.5, p<0.005)$. Stereological analysis revealed that the hypoxia-treated animals had significantly higher absolute numbers of BrdU-labeled cells in the ACC when compared with controls (MANOVA: $F=6.0, p=0.025$; Fig. 3a). No significant differences between the hypoxia-treated rats and the controls 
Fig. 1 Delineation of areas of interest in the ACC, CPU, SVZ and DG
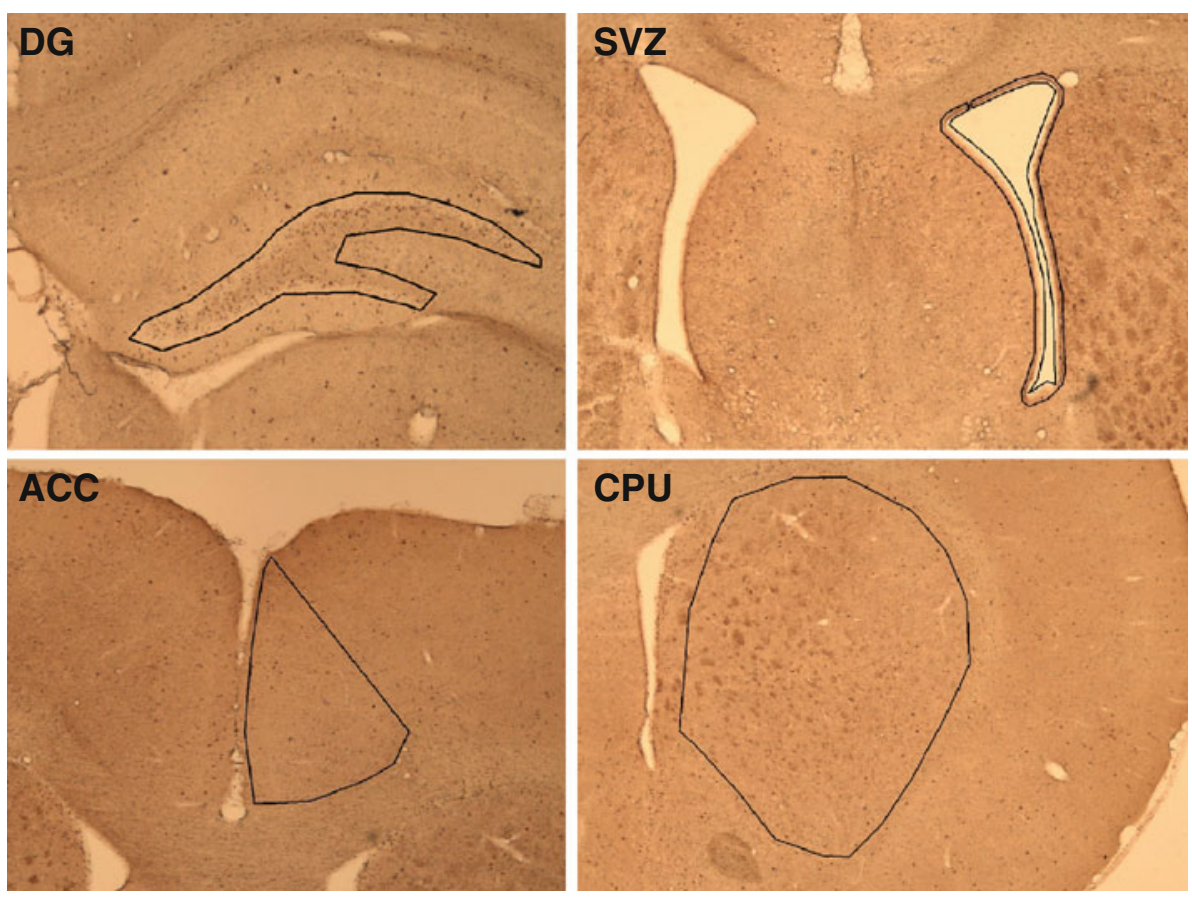

Fig. 2 Sections of BrdUstained cells at 28 days after injection in the ACC, CPU, $\mathrm{SVZ}$ and DG at $\times 50$ magnification
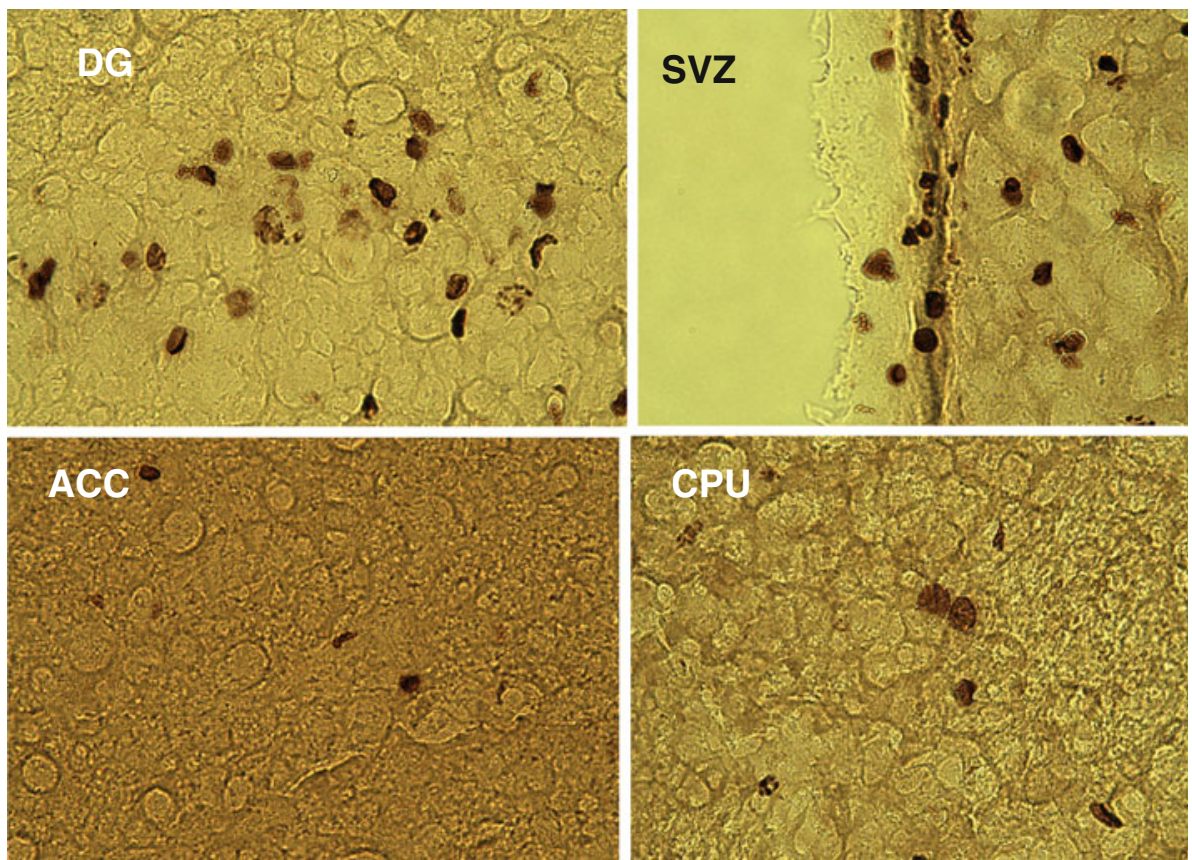

were found in absolute numbers of BrdU-labeled cells in the other brain regions investigated, namely, the CPU, DG and SVZ (all MANOVA: $F=0,0.6,0$ respectively, $p>0.1$; Fig. 3a). Regarding volumes of the regions of interest, the hypoxia-treated animals showed a significant decrease in the total volume of the CPU when compared with controls (MANOVA: $F=12.4, p=0.002$; Fig. 4a). We did not detect any difference between the hypoxiatreated rats and the controls with respect to the total volumes in the areas of interest ACC, DG and SVZ (all MANOVA: $F=0,0.1,0.2$ respectively, $p>0.5$; Fig. $4 \mathrm{a}$ ).

Postnatal day 39

On PD 39, the hypoxia-treated rats showed significantly lower body weight than controls (hypoxia: $179.0 \pm$ 16.63 g vs. controls: $197.5 \pm 20.17 \mathrm{~g}$; ANOVA: $F=5.0$, $p=0.038$ ). Stereological analysis showed that there were 


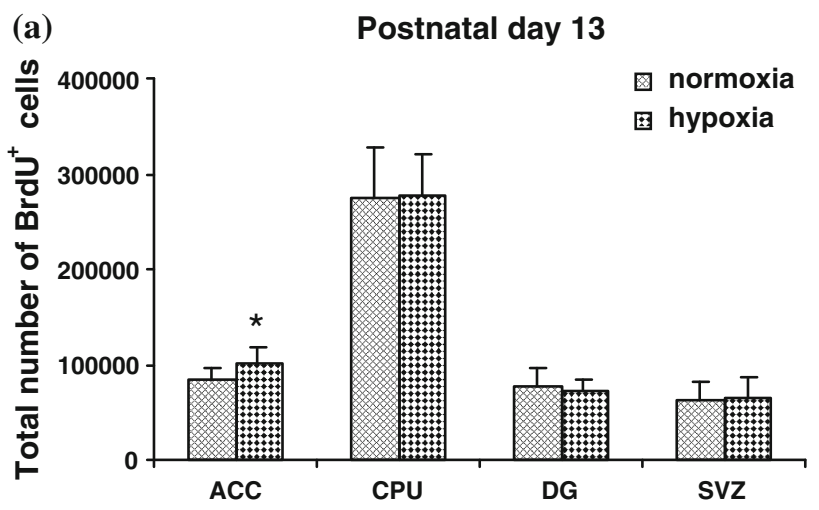

(b)

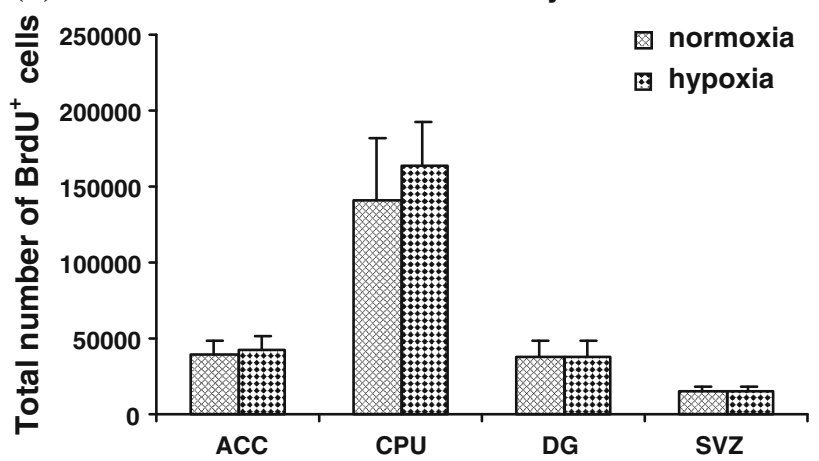

Fig. 3 a Stereological analysis of cell proliferation in the anterior cingulate cortex $(A C C)$, caudate-putamen $(C P U)$, dentate gyrus $(D G)$, and subventricular zone $(S V Z)$, as measured in rats injected with BrdU and killed 2 days later. Data are reported as mean $\pm \mathrm{SD}(n=10$ per group). The total estimated number of BrdU-positive cells was significantly increased in the ACC of hypoxia-treated rats when compared with normoxia (control) animals at postnatal day 13. No differences were observed in the number of BrdU-labeled cells between hypoxia-treated and control rats in the CPU, DG, and SVZ. $* P<0.05$, MANOVA. BrdU, 5-bromo-2-deoxyuridine. b Stereological analysis of survival of newly generated cells in the anterior cingulate cortex $(A C C)$, caudate-putamen $(C P U)$, dentate gyrus $(D G)$, and subventricular zone $(S V Z)$, as measured in rats injected with BrdU and killed 28 days later. Data are reported as mean $\pm \operatorname{SD}(n=10$ per group). No differences were observed in the total estimated number of BrdU-positive cells between hypoxia-treated rats and normoxia (control) animals in the ACC, CPU, DG, and SVZ at postnatal day 39. BrdU, 5-bromo-2-deoxyuridine

no significant differences between the hypoxia-treated animals and the controls with respect to the absolute numbers of BrdU-labeled cells in the investigated brain regions, i.e., ACC, CPU, DG and SVZ (all MANOVA: $F=0.6,2.0,0,0.2$ respectively, $p>0.1$; Fig. 3b). With respect to volumes of the regions of interest, the hypoxiatreated animals showed a significant decrease in the total volume of the ACC when compared with controls (MANOVA: $F=5.0, \quad p=0.044$; Fig. $4 b$ ). However, multivariate analysis revealed an effect of weight on the total volume of the ACC in the hypoxia-treated rats (MANOVA: $F=13.6, p=0.002$ ). We did not detect any difference between the hypoxia-treated rats and the
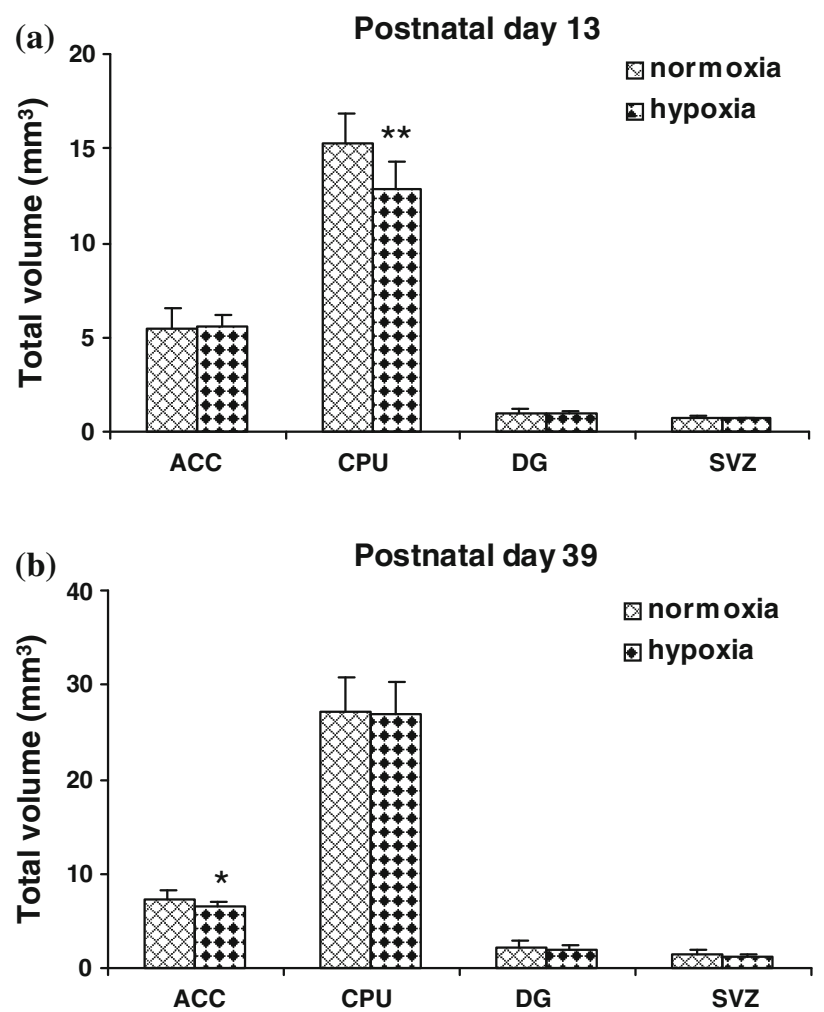

Fig. 4 a Volumes of the areas of interest anterior cingulate cortex $(A C C)$, caudate-putamen $(C P U)$, dentate gyrus $(D G)$, and subventricular zone (SVZ) measured in sections used for stereological counts of BrdU-positive cells in rats injected with BrdU and killed 2 days later. Data are reported as mean $\mathrm{mm}^{3} \pm \mathrm{SD}$ ( $n=10$ per group). The total CPU volume was significantly decreased in hypoxia-treated rats when compared with normoxia (control) animals at postnatal day 13 . No differences were observed in ACC, DG, and SVZ volumes between hypoxia-treated and control rats at postnatal day 13 . $* * P<0.001$, MANOVA. BrdU, 5-bromo-2-deoxyuridine. b Volumes of the areas of interest anterior cingulate cortex $(A C C)$, caudateputamen $(C P U)$, dentate gyrus $(D G)$, and subventricular zone $(S V Z)$ measured in sections used for stereological counts of BrdU-positive cells in rats injected with BrdU and killed 28 days later. Data are reported as mean $\mathrm{mm}^{3} \pm \mathrm{SD}$ ( $n=10$ per group). The total ACC volume was significantly decreased in hypoxia-treated rats when compared with normoxia (control) animals at postnatal day 39. No differences were observed in CPU, DG, and SVZ volumes between hypoxia-treated and control rats at postnatal day 39 . $* P<0.05$, MANOVA. BrdU, 5-bromo-2-deoxyuridine

controls with respect to the total volume in the CPU, DG and SVZ (all MANOVA: $F=0.1,2.3,1.5$ respectively, $p>0.1$; Fig. $4 b$ ).

\section{Discussion}

The main finding of this study was that cell proliferation was significantly increased by $20 \%$ in the ACC of hypoxia-treated rats at PD 13 (5 days after the cessation of hypoxia). The study also showed that total volume of the CPU was significantly decreased by $16 \%$ in hypoxia-treated 
rats at $\mathrm{PD}$ 13. At $\mathrm{PD} 39$ in the $\mathrm{ACC}$, we did not find differences in the number of proliferating cells, but the volume of this region of interest was lower in the hypoxia animals, possibly concealing alterations in the hypoxia group. The unchanged volumes of the other regions of interest, where proliferating cells were counted, point to the validity of our comparison between study groups.

The finding of increased cell proliferation at PND 13 in our neonatal rat model of chronic hypoxia is only partially in line with other studies in animal models of neonatal hypoxia, since we have found increased cell proliferation but in a different brain area from those reported in other models. In schizophrenia, a post-mortem study showed decreased cell proliferation in the dentate gyrus (Reif et al. 2006) and it has been hypothesized that neonatal hypoxia may contribute to these findings. Our animal model of chronic neonatal hypoxia does not support the hypothesis of environmental factors contributing to altered cell proliferation in the hippocampus. However, in a model of brief hypoxia in newborn rats, where pups were exposed within $24 \mathrm{~h}$ after birth to $100 \%$ nitrogen $\left(\mathrm{N}_{2}\right)$ for 5 or $20 \mathrm{~min}$ at $36{ }^{\circ} \mathrm{C}$, the number of proliferative cells was found to be increased in the SVZ and hippocampal DG of 21-day-old pups (Daval et al. 2004; Pourié et al. 2006; Blaise et al. 2009). In a model of transient hypoxia in mice, which were reared in a low-oxygen environment $\left(9.5-10.5 \% \mathrm{O}_{2}\right)$ from PD 3 to 11, a marked increase in cell proliferation was observed in the SVZ at PD 18, 7 days after the cessation of hypoxia (Fagel et al. 2006). In our animal model of $6 \mathrm{~h}$ hypoxia per day from PD 4-8 we may fail to show alterations in the hippocampus or SVZ due to possibly weaker effects of the applied hypoxia. Moreover, our findings of increased cell proliferation only in the ACC following chronic neonatal hypoxia in rats are not in accordance with findings in two animal models of schizophrenia. Keilhoff et al. (2004b) reported increased number of proliferative cells in the hippocampal SGZ in ketamine-treated rats aged 2 months, an animal model of schizophrenia. Ketamine has been shown to mimic behavioral and biological correlates of schizophrenia in animals (Becker et al. 2003; Bernstein et al. 2003; Keilhoff et al. 2004a). Manning et al. (2012) documented increased number of proliferative cells in the granule cell layer of the DG in phospholipase C- $\beta 1$ knockout mice aged 2 months, which show several schizophrenia-like endophenotypes. To our knowledge, the present study is the first to demonstrate increased cell proliferation in the ACC in an animal model of neonatal hypoxia, a brain area that appears to be critically involved in the pathophysiology of schizophrenia (Job et al. 2002; Fornito et al. 2008; Witthaus et al. 2009; Lui et al. 2009). The ACC has been shown to be involved in other environmental risk factors of schizophrenia such as urban upbringing (Lederbogen et al. 2011). In post-mortem studies of schizophrenia patients, in this region neuronal density and neuronal size has been shown to be decreased (Benes et al. 1986; Benes and Bird 1987).

The mechanisms by which neonatal hypoxia may induce cell proliferation remain to be elucidated. Keilhoff et al. (2004b) hypothesize that in their animal model of schizophrenia, ketamine may evoke its stimulating effect on hippocampal neurogenesis by blocking the NMDA receptor directly via reduction of c-Fos and c-Jun expression, leading to a depression of the AP1 transcription factor complex, and/or via a reduced NO production or an enhanced serotonergic activity. In our animal model of chronic neonatal hypoxia, at PD 13, rats exhibited decreased NMDA receptor binding in the ACC, frontal regions, nucleus accumbens, and hippocampus along with a compensatory upregulation of NR1 mRNA (Schmitt et al. 2007), which suggests an involvement of the NMDA receptor in the pathophysiology of hypoxia-induced alterations, including enhanced cell proliferation.

Our data of reduced striatum (CPU) volume at PD 13 is consistent with findings of volumetric deficits in multiple brain regions, including the striatum (caudate nuclei, nucleus accumbens, putamen) in never-medicated, firstepisode schizophrenic patients (Corson et al. 1999; Lieberman et al. 2001; Job et al. 2002; Chua et al. 2007; Glenthoj et al. 2007; Kaspárek et al. 2007; Fornito et al. 2008; Witthaus et al. 2009; Lui et al. 2009; Watson et al. 2012; Asami et al. 2012), when many confounders such as age of onset, duration of illness and medication are reduced or absent. However, except the volume of CPU we did not measure volumes or neuronal cell numbers in other brain regions of hypoxia-treated rats and hypoxia may cause apoptosis-induced cell loss. Indeed, combined hypoxiaischemia has been shown to induce aberrant DNA synthesis along with apoptosis as revealed by BrdU and transferasemediated biotinylated UTP nick end labeling (TUNEL) double-staining (Kuan et al. 2004; Burns et al. 2007). Thus, although these damaged neurons enter the S-phase, they might die due to apoptosis without differentiating into new neurons. Aberrant activation of the cell cycle machinery is known to induce apoptosis and delayed neuronal death after hypoxia-ischemia (Katchanow et al. 2001). However, in our study the ischemic component has not been applied. But a previous $20 \mathrm{~min}$ induction of severe neonatal hypoxia revealed delayed cell death in the hippocampal region CA1, reflecting apoptosis followed by increased neurogenesis (Daval et al. 2004). A 5-min hypoxia period again did not induce apoptosis (Blaise et al. 2009; Pourié et al. 2006). Hence the severity of hypoxia seems to influence the incidence of apoptosis which should be further investigated in our animal model.

Since we did not investigate the development of proliferating cells into neurons or glial cells further studies are 
needed to address this issue. One of these is, e.g., the study of Fagel and co-workers reporting that chronic perinatal hypoxia in mice leads to an increase of astroglial cell proliferation in the subventricular zone. On day 28 , in the cerebral cortex the number of BrdU-positive cells increased and differentiated into oligodendrocytes $(45 \%)$ and astrocytes (35\%) while only $10 \%$ were identified as neurons. However, in the neocortex, twice as many BrdUlabeled cells expressed neuronal markers compared to controls (Fagel et al. 2006). In addition, survival of immature neurons is known to be affected by higher BrdU concentrations over $50 \mathrm{mg} / \mathrm{kg}$ such as applied by ourselves. Moreover, despite the selection of BrdU-positive cells along morphological criteria like cell size and shape, counting of stained microglia cannot be excluded and the findings of increased cell proliferation in the ACC might be influenced by microglial reaction. We did not measure behavioral alterations like deficits in PPI after neonatal hypoxia and behavior might be altered by BrdU-induced cell death of hippocampal neurons. However, stress induced by behavioral testing possibly also influences cell proliferation (Jayatissa and Henningsen 2010) for which reason we decided against performing PPI measurements. Besides, we did not find PPI differences in this young age group before puberty in our previous study (Fendt et al. 2008). Further investigations should include measurements of cell proliferation in rats exposed to neonatal hypoxia during adulthood, when symptoms of the disease occur.

In summary, we have shown alterations in cell proliferation and volume of the CPU after repeated hypoxia in brain regions involved in the pathophysiology of schizophrenia. The results of the present study, together with those in previous studies showing the association between chronic neonatal hypoxia and schizophrenia-related behavioral alterations in postnatal rats (Schmitt et al. 2007; Fendt et al. 2008), support the hypothesis that neonatal hypoxic brain injury may be one of several causal factors for abnormalities in behavioral development and subsequent schizophrenia.

Acknowledgments We would like to thank Mrs. Daniela ReichErkelenz for English text revision and Mrs. Ulrike Heinze for technical assistance.

Open Access This article is distributed under the terms of the Creative Commons Attribution License which permits any use, distribution, and reproduction in any medium, provided the original author(s) and the source are credited.

\section{References}

Altman J, Bayer SA (1990) Migration and distribution of two populations of hippocampal granule cell precursors during the perinatal and postnatal periods. J Comp Neurol 301:365-381
Asami T, Bouix S, Whitford TJ, Shenton ME, Salisbury DF, McCarley RW (2012) Longitudinal loss of gray matter volume in patients with first-episode schizophrenia: DARTEL automated analysis and ROI validation. Neuroimage 59:986-996

Becker A, Peters B, Schroeder H, Mann T, Huether G, Grecksch G (2003) Ketamine-induced changes in rat behaviour: a possible animal model of schizophrenia. Prog Neuropsychopharmacol Biol Psychiatry 27:687-700

Bédard A, Parent A (2004) Evidence of newly generated neurons in the human olfactory bulb. Brain Res Dev Brain Res 151:159-168

Benes FM, Bird ED (1987) An analysis of the arrangement of neurons in the cingulate cortex of schizophrenic patients. Arch Gen Psychiatry 44(7):608-616

Benes FM, Davidson J, Bird ED (1986) Quantitative cytoarchitectural studies of the cerebral cortex of schizophrenics. Arch Gen Psychiatry 43(1):31-35

Bernstein HG, Becker A, Keilhoff G, Spilker C, Gorczyca A, Braunewell KH et al (2003) Brain region-specific changes in the expression of calcium sensor proteins after repeated application of ketamine to rats. Neurosci Lett 339:95-98

Blaise SA, Nédélec E, Alberto JM, Schroeder H, Audonnet S, Bossenmeyer-Pourié C, Guéant JL, Daval JL (2009) Short hypoxia could attenuate the adverse effects of hyperhomocysteinemia on the developing rat brain by inducing neurogenesis. Exp Neurol 216:231-238

Braff DL, Grillon C, Geyer MA (1992) Gating and habituation of the startle reflex in schizophrenic patients. Arch Gen Psychiatry 49:206-215

Burns KA, Ayoub AE, Breunig JJ et al (2007) Nestin-CreER mice reveal DNA synthesis by nonapoptotic neurons following cerebral ischemia-hypoxia. Cereb Cortex 17:2585-2592

Cannon TD, Rosso IM, Bearden CE, Sanchez LE, Hadley T (1999) A prospective cohort study of neurodevelopmental processes in the genesis and epigenesis of schizophrenia. Dev Psychopathol 11:467-485

Cannon TD, Van Erp TG, Rosso IM, Huttunen M, Lonnqvist J, Pirkola T, Salonen O, Valanne L, Poutanen VP, StandertskjoldNordenstam CG (2002) Fetal hypoxia and structural brain abnormalities in schizophrenic patients, their siblings, and controls. Arch Gen Psychiatry 59:35-41

Chua SE, Cheung C, Cheung V, Tsang JT, Chen EY, Wong JC, Cheung JP, Yip L, Tai KS, Suckling J, McAlonan GM (2007) Cerebral grey, white matter and CSF in never-medicated, firstepisode schizophrenia. Schizophr Res 89:12-21

Corson PW, Nopoulos P, Andreasen NC, Heckel D, Arndt S (1999) Caudate size in first-episode neuroleptic-naive schizophrenic patients measured using an artificial neural network. Biol Psychiatry 46:712-720

Dalman C, Thomas HV, David AS, Gentz J, Lewis G, Allebeck P (2001) Signs of asphyxia at birth and risk of schizophrenia. Population-based case-control study. $\mathrm{Br} \quad \mathrm{J}$ Psychiatry 179:403-408

Daval JL, Pourié G, Grojean S, Lièvre V, Strazielle C, Blaise S, Vert $\mathrm{P}$ (2004) Neonatal hypoxia triggers transient apoptosis followed by neurogenesis in the rat CA1 hippocampus. Pediatr Res 55:561-567

Dobbing J, Sands J (1979) Comparative aspects of the brain growth spurt. Early Hum Dev 3:79-83

Ehninger D, Kempermann G (2008) Neurogenesis in the adult hippocampus. Cell Tissue Res 331:243-250

Fagel DM, Ganat Y, Silbereis J, Ebbitt T, Stewart W, Zhang H, Ment LR, Vaccarino FM (2006) Cortical neurogenesis enhanced by chronic perinatal hypoxia. Exp Neurol 199:77-91

Fendt M, Lex A, Falkai P, Henn FA, Schmitt A (2008) Behavioural alterations in rats following neonatal hypoxia and effects of 
clozapine: implications for schizophrenia. Pharmacopsychiatry 41:138-145

Fornito A, Yücel M, Wood SJ, Adamson C, Velakoulis D, Saling MM, McGorry PD, Pantelis C (2008) Surface-based morphometry of the anterior cingulate cortex in first episode schizophrenia. Hum Brain Mapp 29:478-489

Glenthoj A, Glenthoj BY, Mackeprang T, Pagsberg AK, Hemmingsen RP, Jernigan TL, Baaré WF (2007) Basal ganglia volumes in drug-naive first-episode schizophrenia patients before and after short-term treatment with either a typical or an atypical antipsychotic drug. Psychiatry Res 154:199-208

Gould E, Reeves AJ, Graziano MS, Gross CG (1999) Neurogenesis in the neocortex of adult primates. Science 286:548-552

Gratzner HG (1982) Monoclonal antibody to 5-bromo- and 5-iododeoxyuridine: a new reagent for detection of DNA replication. Science 218:474-475

Gundersen HJ, Bagger P, Bendtsen TF et al (1988) The new stereological tools: disector, fractionator, nucleator and point sampled intercepts and their use in pathological research and diagnosis. APMIS 96:857-881

Ikonomidou C, Mosinger JL, Salles KS, Labruyere J, Olney JW (1989) Sensitivity of the developing rat brain to hypobaric/ ischemic damage parallels sensitivity to $\mathrm{N}$-methyl-aspartate neurotoxicity. J Neurosci 9:2809-2818

Jayatissa MN, Henningsen K, Nikoajsen G et al (2010) A reduced number of hippocampal granule cells does not associate with an anhedonia-like phenotype in a rat chronic stress model of depression. Stress 13:95-105

Job DE, Whalley HC, McConnell S, Glabus M, Johnstone EC, Lawrie SM (2002) Structural gray matter differences between firstepisode schizophrenics and normal controls using voxel-based morphometry. Neuroimage 17:880-889

Kaspárek T, Prikryl R, Mikl M, Schwarz D, Cesková E, Krupa P (2007) Prefrontal but not temporal grey matter changes in males with first-episode schizophrenia. Prog Neuropsychopharmacol Biol Psychiatry 31:151-157

Katchanow J, Harms C, Gertz K et al (2001) Mild cerebral ischemia induces loss of cyclin-dependent kinase inhibitors and activation of cell cycle machinery before delayed neuronal cell death. J Neuroscience 21:5045-5053

Keilhoff G, Becker A, Grecksch G, Wolf G, Bernstein HG (2004a) Repeated application of ketamine to rats induces changes in the hippocampal expression of parvalbumin, nNOS and cFOS similar to those found in human schizophrenia. Neuroscience 126:591-598

Keilhoff G, Bernstein HG, Becker A, Grecksch G, Wolf G (2004b) Increased neurogenesis in a rat ketamine model of schizophrenia. Biol Psychiatry 56:317-322

Kodama M, Fuijoka T, Duman RS (2004) Chronic olanzapine or fluoxetine administration increases cell proliferation in hippocampus and prefrontal cortex of adult rat. Biol Psychiatry 56(8):570-580

Kuan C-Y, Schloemer AJ, Lu A et al (2004) Hypoxia-ischemia induces DNA synthesis without cell proliferation in dying neurons in adult rodent brain. Neurobiol Dis 24:10763-10772

Kuhn HG, Dickinson-Anson H, Gage FH (1996) Neurogenesis in the dentate gyrus of the adult rat: age-related decrease of neuronal progenitor proliferation. J Neurosci 16:2027-2033

Lederbogen F, Kirsch P, Haddad L, Streit F, Tost H, Schuch P, Wüst S, Pruessner JC, Rietschel M, Deuschle M, Meyer-Lindenberg A (2011) City living and urban upbringing affect neural social stress processing in humans. Nature 474(7352):498-501

Lieberman J, Chakos M, Wu H, Alvir J, Hoffman E, Robinson D, Bilder R (2001) Longitudinal study of brain morphology in first episode schizophrenia. Biol Psychiatry 49:487-499
Lui S, Deng W, Huang X, Jiang L, Ma X, Chen H, Zhang T, Li X, Li D, Zou L, Tang H, Zhou XJ, Mechelli A, Collier DA, Sweeney JA, Li T, Gong Q (2009) Association of cerebral deficits with clinical symptoms in antipsychotic-naive first-episode schizophrenia: an optimized voxel-based morphometry and resting state functional connectivity study. Am J Psychiatry 166: 196-205

Madsen TM, Yeh DD, Valentine GW, Duman RS (2005) Electroconvulsive seizure treatment increases cell proliferation in rat frontal cortex. Neuropsychopharmacology 30(1):27-34

Manning EE, Ransome MI, Burrows EL, Hannan AJ (2012) Increased adult hippocampal neurogenesis and abnormal migration of adult-born granule neurons is associated with hippocampalspecific cognitive deficits in phospholipase $\mathrm{C}-\beta 1$ knockout mice. Hippocampus 22:309-319

McNeil TF, Cantor-Graae E, Ismail B (2000a) Obstetric complications and congenital malformation in schizophrenia. Brain Res Brain Res Rev 31:166-178

McNeil TF, Cantor-Graae E, Weinberger DR (2000b) Relationship of obstetric complications and differences in size of brain structures in monozygotic twin pairs discordant for schizophrenia. Am J Psychiatry 157:203-212

McOmish CE, Burrows E, Howard M, Scarr E, Kim D, Shin HS, Dean B, van den Buuse M, Hannan AJ (2008a) Phospholipase Cbeta1 knockout mice exhibit endophenotypes modeling schizophrenia which are rescued by environmental enrichment and clozapine administration. Mol Psychiatry 13:661-672

McOmish CE, Burrows EL, Howard M, Hannan AJ (2008b) PLCbeta1 knockout mice as a model of disrupted cortical development and plasticity: behavioral endophenotypes and dysregulation of RGS4 gene expression. Hippocampus 18:824834

Paxinos G, Watson C (1986) The rat brain in stereotaxic coordinates. 2nd edn. Academic Press, San Diego

Pencea V, Bingaman KD, Wiegand SJ, Luskin MB (2001) Infusion of brain-derived neurotrophic factor into the lateral ventricle of the adult rat leads to new neurons in the parenchyma of the striatum, septum, thalamus, and hypothalamus. J Neurosci 21:6706-6717

Pourié G, Blaise S, Trabalon M, Nédélec E, Guéant JL, Daval JL (2006) Mild, non-lesioning transient hypoxia in the newborn rat induces delayed brain neurogenesis associated with improved memory scores. Neuroscience 140:1369-1379

Reif A, Fritzen S, Finger M, Strobel A, Lauer M, Schmitt A, Lesch KP (2006) Neural stem cell proliferation is decreased in schizophrenia, but not in depression. Mol Psychiatry 11(5): 514-522

Schmitt A, Fendt M, Zink M, Ebert U, Starke M, Berthold M, Herb A, Petroianu G, Falkai P, Henn FA (2007) Altered NMDA receptor expression and behavior following postnatal hypoxia: potential relevance to schizophrenia. J Neural Transm 114:239-248

Schmitz C (1998) Variation of fractionator estimates and its prediction. Anat Embryol (Berl) 198:371-397

Schmitz C, Hof PR (2000) Recommendations for straightforward and rigorous methods of counting neurons based on a computer simulation approach. J Chem Neuroanat 20:93-114

Schmitz C, Hof PR (2005) Design-based stereology in neuroscience. Neuroscience 130:813-831

Shapiro EM, Gonzalez-Perez O, Manuel García-Verdugo J, AlvarezBuylla A, Koretsky AP (2006) Magnetic resonance imaging of the migration of neuronal precursors generated in the adult rodent brain. Neuroimage 32:1150-1157

Sommer JU, Schmitt A, Heck M, Schaeffer EL, Fendt M, Zink M, Nieselt K, Symons S, Petroianu G, Lex A, Herrera-Marschitz M, Spanagel R, Falkai P, Gebicke-Haerter PJ (2010) Differential expression of presynaptic genes in a rat model of postnatal 
hypoxia: relevance to schizophrenia. Eur Arch Psychiatry Clin Neurosci 260(Suppl 2):S81-S89

Sterio DC (1984) The unbiased estimation of number and sizes of arbitrary particles using the disector. J Microsc 134:127-136

Van den Buuse M, Garner B, Koch M (2003) Neurodevelopmental animal models of schizophrenia: effects on prepulse inhibition. Curr Mol Med 3:459-471

Van Erp TG, Saleh PA, Rosso IM, Huttunen M, Lönnqvist J, Pirkola T, Salonen O, Valanne L, Poutanen VP, Standertskjöld-Nordenstam CG, Cannon TD (2002) Contributions of genetic risk and fetal hypoxia to hippocampal volume in patients with schizophrenia or schizoaffective disorder, their unaffected siblings, and healthy unrelated volunteers. Am J Psychiatry 159:1514-1520

Verdoux H, Geddes JR, Takei N, Lawrie SM, Bovet P, Eagles JM, Heun R, McCreadie RG, McNeil TF, O'Callaghan E, Stober G, Willinger MU, Wright P, Murray RM (1997) Obstetric complications and age at onset in schizophrenia: an international collaborative meta-analysis of individual patient data. Am J Psychiatry 154:1220-1227

Watson DR, Anderson JM, Bai F, Barrett SL, McGinnity TM, Mulholland CC, Rushe TM, Cooper SJ (2012) A voxel based morphometry study investigating brain structural changes in first episode psychosis. Behav Brain Res 227:91-99

Weinberger DR (1996) On the plausibility of "the neurodevelopmental hypothesis" of schizophrenia. Neuropsychopharmacology $14: 1-11$

West MJ (1999) Stereological methods for estimating the total number of neurons and synapses: issues of precision and bias. Trends Neurosci 22:51-61

West MJ, Slomianka L, Gundersen HJ (1991) Unbiased stereological estimation of the total number of neurons in the subdivisions of the rat hippocampus using the optical fractionator. Anat Rec 231:482-497

Witthaus H, Kaufmann C, Bohner G, Ozgürdal S, Gudlowski Y, Gallinat J, Ruhrmann S, Brüne M, Heinz A, Klingebiel R, Juckel G (2009) Gray matter abnormalities in subjects at ultra-high risk for schizophrenia and first-episode schizophrenic patients compared to healthy controls. Psychiatry Res 173:163-169

Yamashima T, Tonchev AB, Yukie M (2007) Adult hippocampal neurogenesis in rodents and primates: endogenous, enhanced, and engrafted. Rev Neurosci 18:67-82 